\title{
Anomalous Origin of the Right Coronary Artery from the Left Coronary Sinus Case report
}

"Ziyab K. Sarfaraz, ${ }^{1}$ Mohammad S. Siddiqi, ${ }^{2}$ Adil H. Al-Kindi, ${ }^{2}$ Tarek Alameddine ${ }^{2}$

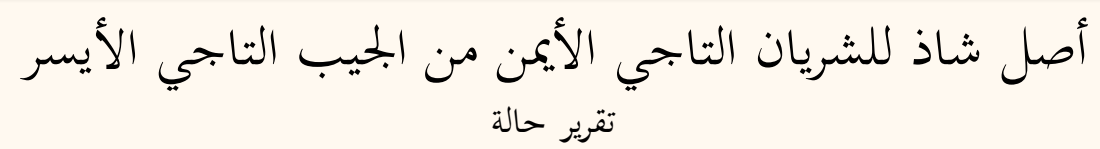

ذياب خان سارفاراز، محمد سلمان صدقي، عادل هـاشم الكندي، طارق علم الدين

ABSTRACT: The anomalous origin of the right coronary artery from the left coronary sinus is a rare congenital disorder and can often result in sudden death upon initial presentation. We report a 19-year-old male patient who was referred to the Sultan Qaboos University Hospital, Muscat, Oman, in 2015 with multiple episodes of exertional angina. He was diagnosed as having an anomalous right coronary artery arising from the left coronary sinus following an intraoperative transesophageal echocardiogram. An unroofing ostioplasty of the anomalous right coronary artery was successful. Details of the surgical management of this anomaly are discussed.

Keywords: Congenital Abnormalities; Coronary Artery; Coronary Sinus; Anatomic Variation; Myocardial Ischemia; Case Report; Oman.

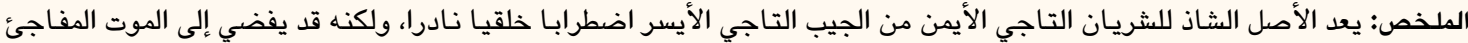

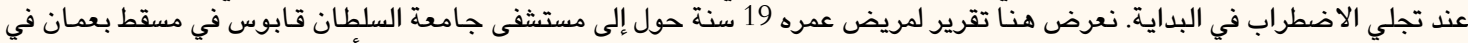

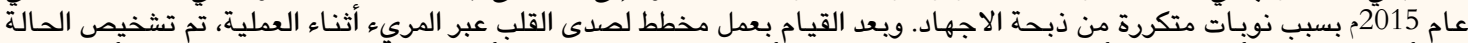

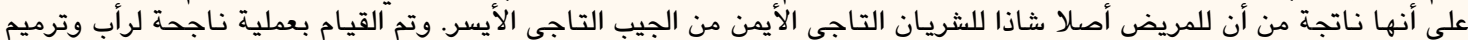

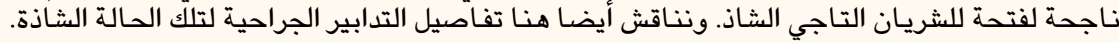

الكلمات المفتاحية: الاضرابات الخلقية؛ الثريان التاجي؛ الجيب التاجي؛ اختلاف تثريحي؛ إقفار عضلي قلبي؛ تقرير حالة؛ عمان.

C ONGenital anomalous origin of THE right coronary artery from the left coronary with sudden death or myocardial ischaemia. ${ }^{1}$ Thus, aggressive management is usually recommended at diagnosis. This case report describes a 19-year-old man with an anomalous origin of the right coronary artery from the left coronary sinus who underwent successful surgical management.

\section{Case Report}

A 19-year-old morbidly obese male patient was referred from a peripheral hospital to the cardiology service at the Sultan Qaboos University Hospital, Muscat, Oman, in 2015 with a seven-month history of intermittent substernal exertional chest pain (Canadian Cardiovascular Society grade II) associated with diaphoresis, palpitations and dizziness. In addition, he also suffered from insulin-dependent diabetes mellitus and adult-onset Still's disease. At the previous hospital, he had initially been treated as a case of acute coronary syndrome as his echocardiography results were reportedly normal. However, 24-hour Holter monitoring had shown seven premature supraventricular ectopic beats and an exercise stress test had been prematurely terminated due to the patient's poor exercise tolerance.

Since the findings were inconclusive and the patient had a history of recurrent chest pain, a cardiac computed tomography (CT) scan was performed which showed an anomalous origin of the right coronary artery (RCA) from the left coronary sinus. The RCA passed between the root of the aorta and the main pulmonary artery. Moderate narrowing of the proximal segment and the ostium was noted [Figure 1]. Considering the CT findings and the patient's history of ischaemic heart disease, a coronary angiogram and a myocardial perfusion scan were carried out. The coronary angiogram showed a codominant system with no other apparent abnormalities apart from the anomalous RCA. The patient subsequently underwent a technetium-99m stress test which showed normal myocardial uptake. However, the anomalous course 

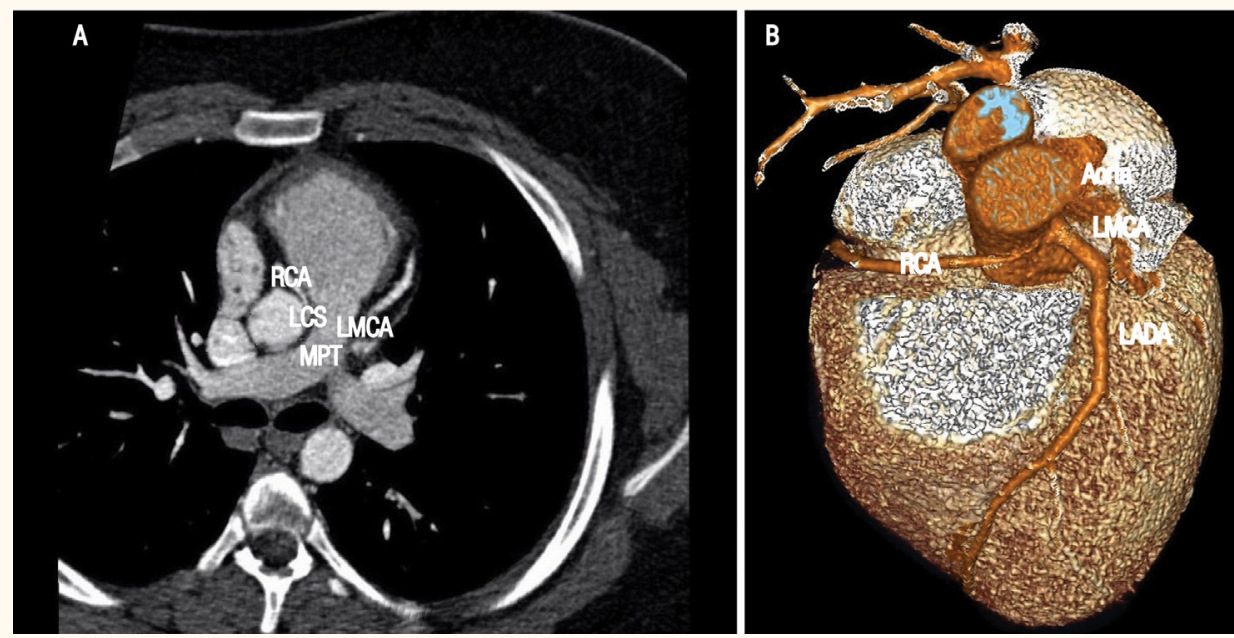

Figure 1: A: Cardiac computed tomography (CT) scan of a 19-year-old male patient showing the anomalous course of the right coronary artery (RCA) arising from the left coronary sinus. B: Three-dimensional cardiac CT reconstruction of the anomalous RCA.

$R C A=$ right coronary artery; $L C S=$ left coronary sinus; $L M C A=$ left main coronary artery; $M P T=$ main pulmonary trunk; $L A D A=l e f t$ anterior descending artery.

of the RCA, together with the narrowing of the proximal segment, made the patient more susceptible to ischaemic events and sudden death.

The patient was referred to the Sultan Qaboos University Hospital for further management. An intraoperative transoesophageal echocardiogram was done in which the RCA was clearly visualised as arising from the left coronary sinus [Figure 2]. Accordingly, an unroofing ostioplasty of the anomalous RCA was undertaken. The intraoperative period went smoothly. The aortic cross-clamp and cardiopulmonary bypass time was 45 and 144 minutes, respectively. The postoperative period was uneventful and the patient was discharged five days after the surgery. At a one-year follow-up visit to the outpatient clinic, he denied any further episodes of chest pain and a cardiac CT scan showed that the proximal part of the RCA was wide open with no signs of narrowing.

\section{Discussion}

To the best of the authors' knowledge, this is the first reported case from Oman of an anomalous origin of the right coronary artery from the left coronary sinus. In a prospective angiographic study of 1,950 consecutive adult cases, Angelini et al., reported the incidence of anomalous coronary arteries to be 5.6\%; of these, the incidence of the RCA arising from the left coronary sinus was $0.92 \% .{ }^{1}$ However, even though the incidence is relatively low, the consequences of this type of anomaly are often fatal. ${ }^{1}$

As with the current case, the diagnosis of an anomalous RCA is often made incidentally as physical examinations or tests like electrocardiograms, stress tests and perfusion scans are usually non-revealing. ${ }^{2} \mathrm{~A}$ precise diagnosis is often made as the result of cardiac CT imaging which can provide numerous threedimensional image reconstructions that allow precise evaluation of the origin and course of the anomalous coronary artery. ${ }^{3}$ Other diagnostic modalities, such as coronary angiography, are of limited value because they provide only two-dimensional pictures and cannulation of the aberrant coronary artery can be difficult. ${ }^{4}$ In view of these limitations, cardiac $\mathrm{CT}$ is recommended as the imaging modality of choice in diagnosing such anomalies., ${ }^{2,3}$

Various treatment modalities have been suggested for treating coronary artery anomalies. Kaku et al. proposed conservative therapy, such as

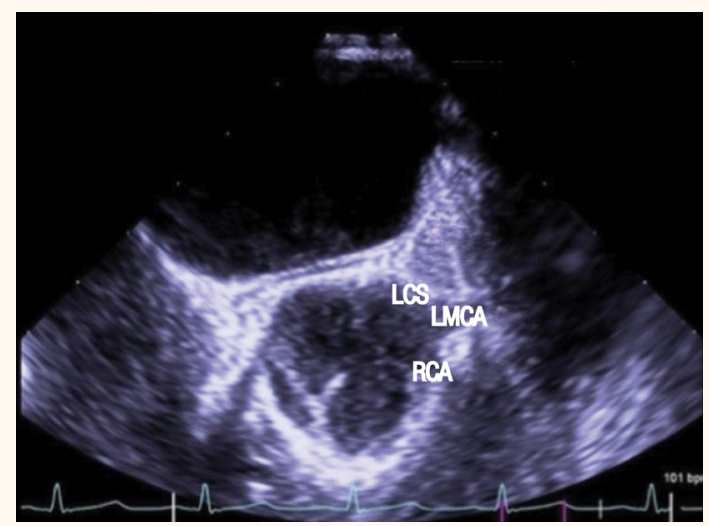

Figure 2: Intraoperative transesophageal echocardiography of a 19-year-old male patient demonstrating the anomalous origin of the right coronary artery from the left coronary sinus.

$L C S$ = left coronary sinus; $L M C A$ = left main coronary artery; $R C A=$ right coronary artery. 
limited exercise and drug therapy (i.e. nitrates, calcium or $\beta$-blockers and antiarrhythmic drugs), with $69.2 \%$ of cases treated using this approach reporting symptomatic improvement. ${ }^{5}$ However, the surgical correction of an anomalous RCA is generally indicated when the anomalous artery traverses interarterially between the aortic root and the pulmonary artery. ${ }^{6}$ This is commonly termed the 'malignant' course, with the artery often passing proximally within the aorta wall (i.e. the intramural segment). During exertion, this intramural segment can transiently narrow due to changes in the pressure and diameter of the pulmonary artery and aorta. ${ }^{6}$ The surgical method of correcting such anomalies remains controversial, with many techniques recommended over the years, including a coronary artery bypass, coronary reimplantation and unroofing of the intramural segment. ${ }^{7-10}$ In 1981, Mustafa et al. first described the use of an unroofing procedure to correct an anomalous left coronary artery anomaly. This technique has since become the procedure of preference for many surgeons, especially if the course of the anomalous coronary artery is intramural. $^{8}$

Using the unroofing approach, a neo-ostium is created in the correct sinus and the course between the pulmonary artery and aorta is eliminated, as well as the intramural course within the aortic wall. This moves the coronary lumen away from the interarterial position and effectively relieves the stenosis. ${ }^{6,7}$ Other techniques such as coronary artery bypass grafting using a saphenous vein or ipsilateral internal mammary artery have been proposed; however, they may be more suitable for older patients with associated atherosclerotic changes. ${ }^{9}$ Performing this type of surgery on younger patients, such as in the present case, may be counterintuitive because the long-term patency of the graft has not been established and the graft may theoretically compete with the normal antegrade flow of the anomalous artery, leading to concerns of graft thrombosis. ${ }^{9}$ Instead, a coronary reimplantation can be considered in which the anomalous coronary artery is ligated and transected proximally and anastomosed in the correct sinus of Valsalva. ${ }^{10}$

\section{Conclusion}

The anomalous origin of the RCA is a potentially fatal congenital condition. An unroofing surgery is the procedure of choice when the course is malignant and intramural. In the current case, a one-year postoperative follow-up indicated that the procedure was successful, with the patient reporting the complete resolution of his symptoms.

\section{References}

1. Angelini P, Villason S, Chan AV Jr, Diez JG. Normal and anomalous coronary arteries in humans. In: Angelini P, Ed. Coronary Artery Anomalies: A comprehensive approach. Philadelphia, Pennsylvania, USA: Lippincott Williams \& Wilkins; 1999. Pp. 27-150.

2. Basso C, Maron BJ, Corrado D, Thiene G. Clinical profile of congenital coronary artery anomalies with origin from the wrong aortic sinus leading to sudden death in young competitive athletes. J Am Coll Cardiol 2000; 35:1493-501. doi: 10.1016/S0735-1097(00)00566-0.

3. Shi H, Aschoff AJ, Brambs HJ, Hoffmann MH. Multislice CT imaging of anomalous coronary arteries. Eur Radiol 2004; 14:2172-81. doi: 10.1007/s00330-004-2490-2.

4. de Jonge GJ, van Ooijen PMA, Piers LH, Dikkers R, Tio RA, Willems TP, et al. Visualization of anomalous coronary arteries on dual-source computed tomography. Eur Radiol 2008; 18:2425-32. doi: 10.1007/s00330-008-1110-y.

5. Kaku B, Shimizu M, Yoshio H, Ino H, Mizuno S, Kanaya H, et al. Clinical features of prognosis of Japanese patients with anomalous origin of the coronary artery. Jpn Circ J 1996; 60:731-41.

6. Gulati R, Reddy VM, Culbertson C, Helton G, Suleman S, Reinhartz $\mathrm{O}$, et al. Surgical management of coronary artery arising from the wrong coronary sinus, using standard and novel approaches. J Thorac Cardiovasc Surg 2007; 134:1171-8. doi: 10.1016/j.jtcvs.2007.02.051

7. Mustafa I, Gula G, Radley-Smith R, Durrer S, Yacoub M. Anomalous origin of the left coronary artery from the anterior aortic sinus: A potential cause of sudden death - Anatomic characterization and surgical treatment. J Thorac Cardiovasc Surg 1981; 82:297-300.

8. Davies JE, Burkhart HM, Dearani JA, Suri RM, Phillips SD, Warnes CA, et al. Surgical management of anomalous aortic origin of a coronary artery. Ann Thorac Surg 2009; 88:844-8. doi: 10.1016/j.athoracsur.2009.06.007.

9. Thomas D, Salloum J, Montalsescot G, Drobinski G, Artigou JY, Grosgogeat Y. Anomalous coronary arteries coursing between the aorta and pulmonary trunk: Clinical indications for coronary artery bypass. Eur Heart J 1991; 12:832-4. doi: 10.10 93/eurheartj/12.7.832.

10. Karimi M, Murdison K, Blackwood W, Davis W. Reimplantation of anomalous right coronary artery from left main coronary artery: A surgical option. Interact Cardiovasc Thorac Surg 2010; 10:642-4. doi: 10.1510/icvts.2009.226464. 